\title{
ARCHIVES
of
}

\section{Some Similarities / Differences between Steel Static and Virtual Brass Static Casting}

\author{
P. Kwapisiński ${ }^{a, *}$, A.A. Ivanova ${ }^{\text {b }}$, B. Kania ${ }^{c}$, W. Wołczyński ${ }^{\text {c }}$ \\ ${ }^{a}$ KGHM - Polish Copper Company, Skłodowskiej-Curie 48, 59-301 Lubin, Poland \\ ${ }^{\mathrm{b}}$ Institute of Applied Mathematics and Mechanics, Rosa Luxemburg 74, 83-114 Donetsk, Ukraine \\ ${ }^{\mathrm{c}}$ Institute of Metallurgy and Materials, Reymonta 25, 30-059 Kraków, Poland \\ *Corresponding author. E-mail address: Piotr.Kwapisiński@kghm.com
}

Received 22.11.2016; accepted in revised form 07.02.2017

\begin{abstract}
An innovative method for determining the structural zones in the large static steel ingots has been described. It is based on the mathematical interpretation of some functions obtained due to simulation of temperature field and thermal gradient field for solidifying massive ingot. The method is associated with the extrema of an analyzed function and with its points of inflection. Particularly, the CET transformation is predicted as a time-consuming transition from the columnar- into equiaxed structure. The equations dealing with heat transfer balance for the continuous casting are presented and used for the simulation of temperature field in the solidifying virtual static brass ingot. The developed method for the prediction of structural zones formation is applied to determine these zones in the solidifying brass static ingot. Some differences / similarities between structure formation during solidification of the steel static ingot and virtual brass static ingot are studied. The developed method allows to predict the following structural zones: fine columnar grains zone, (FC), columnar grains zone, (C), equiaxed grains zone, (E). The FCCT-transformation and CET-transformation are forecast as sharp transitions of the analyzed structures. Similarities between steel static ingot morphology and that predicted for the virtual brass static ingot are described.
\end{abstract}

Keywords: Fundamentals of foundry processes, Mathematical modeling of structure, FCCT and CET transitions, Brass static ingot

\section{Introduction}

A new innovative method for the description of structure formation and especially for the prediction of some structural transformations and resultant situation of structural zones in the steel massive ingot, solidifying as static ingot, has appeared recently, [1]. It is based on the mathematical predictions for the structure appearance in a large steel ingot. It requires to analyze some particular points of the simulated functions which result from the temperature field calculation. In particular, some points of inflection (mathematically significant) are used to define the structural transformations which have been previously described by Prof. J.D. Hunt in his fundamental paper associated with the solid/liquid interface undercooling, [2]. The mentioned innovative mathematical method for the structural zones localization in a given ingot and especially mathematical mode for the predictions of the structural transitions are applied to the description of a virtual brass static casting developed in the current simulations.

The fundamental role of the so-called contact layer (air gap between brass ingot and graphite which covers the mold) is considered in the current heat transfer balance. Therefore, the boundary conditions connected with the air gap are formulated, analogously, as in the model for the mushy zone formation, [3].

The latent heat which plays essential role in the heat transfer balance is introduced into the boundary conditions. Finally, the application of the current method allows to study not only the temperature field but the thermal gradient field as well. 


\section{Forecast of the ingot's structural} zones

The recently developed method for the ingot structure forecast, [1], is connected with the interpretation of the points of inflection if they are presented by the calculated function. The very informative function in this area is the liquidus isotherm velocity plotted versus time of the static ingot solidification.

\subsection{Mathematical forecasts for steel static ingot}

The numerical treatment / simulation allowing for the temperature filed calculation was performed by means of the ABAQUS professional program. It shows the liquidus isotherm velocity plotted versus time of the static ingot solidification, Fig. 1 , in a simplified manner that is in such a way that the ingot shape / geometry is replaced by the roll shape, [4]. As a result, the competition / interplay between the $v$ - rate of the liquidus isotherm movement and the $v \mathrm{~s}$ - rate of the $\mathrm{s} / 1$ interface displacement is presented / interpreted mathematically.

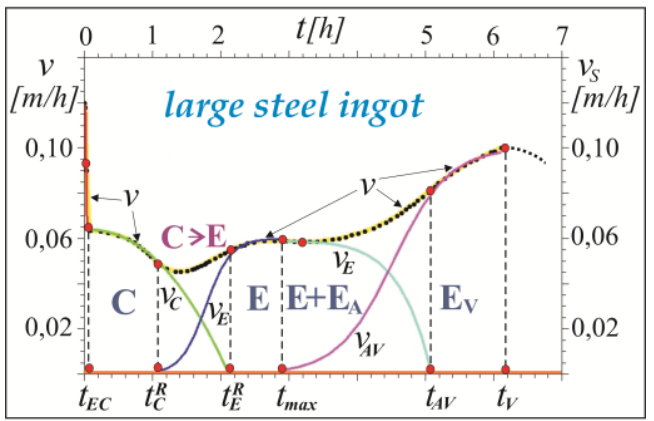

Fig. 1. Correlation / interplay between the $v$ - liquidus isotherm movement and $v_{S}-\mathrm{s} / \mathrm{l}$ interface displacement; $v_{S}=v_{C} ; v_{E} ; v_{A V}$ for columnar, equiaxed, and "A", "V" - segregates zone formation; $t_{E C}$ - time of the chilled equiaxed into columnar structure formation $E \rightarrow C, t C^{R}$, - time of the equiaxed structure birth, $t_{E}^{R}$ time of the columnar structure death; $t_{\max }$ - time of the " $\mathrm{A}$ " segregates appearance; $t_{A V}$ - time of the so-called "switching point", [1], $t_{V}$ - time of the beginning of the "V" segregates vanishing; $\mathrm{C} \rightarrow E$ - the $\mathrm{CE}$ transitions (CET), [1]

Not only points of inflection are useful in the mathematical interpretation of the appearance of some different structure types in the steel static ingot but the extreme points (minima / maxima) of the considered $v$ - function as well, Fig. 1. The function describes:

a) formation of the chilled equiaxed structure in the period of time: $0 \div t_{E C}$; the $v$ - function presents a point of inflection (dot),

b) formation of the columnar structure (cells) in the period of time: $t_{E C} \div t_{E} R$; both liquidus isotherm velocity and $\mathrm{s} / 1$ interface rate (green line extrapolated to zero at the $t_{E}{ }^{R}$ time) are superposed over each other within the period of time: $t_{E C} \div t C^{R}$; next the liquidus isotherm velocity tears away to enable the appearance of the undercooled melt behind it and to promote formation of some nuclei for equiaxed grains,

$t_{E}^{R}$ - time is connected with the point of inflection of the $v$ function,

c) formation of the equiaxed structure which begins at time: $t c^{R}$, this time is connected with the point of inflection of the $v$ - function; the creation of the entirely equiaxed grains reaches its apogee (culminating point) at the $t_{\max }$ - time,

d) formation of the equiaxed grains accompanied by the " $A$ " segregates appearance begins at the $t_{\max }$ - time,

e) transition from the equiaxed grains formation accompanied by the "A" segregates into the equiaxed grains formation accompanied by the "V" segregates formation which occurs at the $t_{A V}$ - time (switching point) connected with the point of inflection; formation of the equiaxed grains accompanied by the "A" segregates appearance is completed at the $t_{A V}$ time (at the mentioned switching point); formation of the equiaxed grains accompanied by the "V" segregates attains its apogee at the $t_{V}$ - time which is connected with the extreme point of the analyzed $v$ - function.

Thus, the switching point of the static ingot is a virtual place / time at which the thermophoresis is the winner in the competition between thermophoresis itself and viscosity gradient. The viscosity gradient is responsible for the formation of the sedimentary cones in the static ingot, whereas the thermophoresis is connected with formation of the solid which evinces the shell / crust shape.

The mentioned analysis shows that the equiaxed structure is dominant in the massive steel ingot subjected to the static solidification. It results from the fact that the static solidification is unsteady process and solidification rate decreases in time due to the slow cooling.

However, some observations of the structure revealed in the continuously cast ingots confirms that the columnar structure is dominant in these castings, Fig. 2. It results from the fact that the continuous casting is the stationary process (apart from the initial transient period of this process) and the cooling is very intensive.

It should be emphasized that the initial transient period of the brass ingots continuous casting follows the steel static ingot solidification to a certain extent, [4].

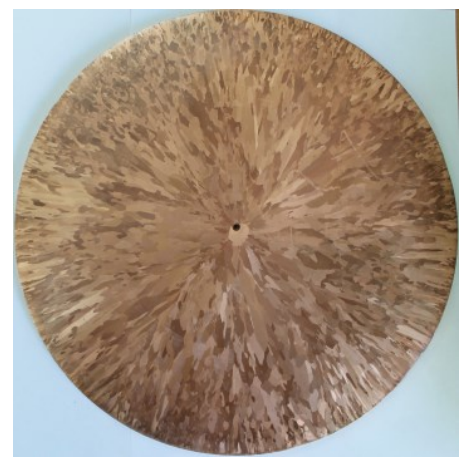

Fig. 2. Transversal section of the continuously cast brass ingot; columnar structure, (C), as a dominant morphology of the continuously solidifying ingot; fine columnar structure, (FC), is situated at the ingot's periphery; equiaxed grains, (E), are hardly visible in the ingot center in the neighborhood of a single crystal which is localized axially 
The static ingot solidification was the subject of some simulations in order to predict the "A" - segregates formation, [5], and the CET appearance, [6]-[22]. Generally, the different numerical method of the temperature field simulation were applied in the these models, [6], [12], [14], [17], [19], [21]. Particularly some attempts were made to describe the difference between columnar and equiaxed grains creation, [7]-[11], [13], [15]-[16], [18], [20], [22]. In the current model the temperature field is calculated and transformed into thermal gradient field. It allows to show the CET situation for different thicknesses of the mold, Fig. 3. It is confirmed that the CET is time consuming transition, Fig. 3. It means that the columnar- and equiaxed structure must co-exist within the period of time when the CET occurs. Therefore, the experimental observations of the steel morphology were made due to vertical cut at the mid-depth of the 15-tons forging steel ingot serially cast by the CELSA-Huta Ostrowiec plant in Ostrowiec Świętokrzyski, Fig. 4.

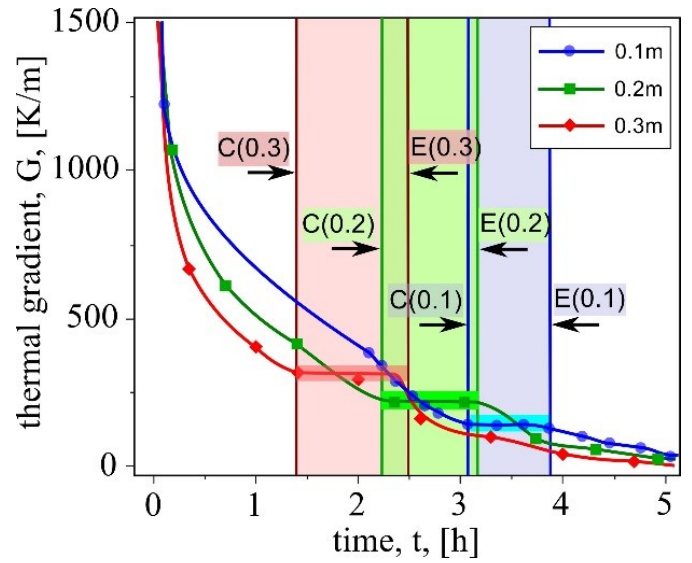

Fig. 3. Thermal gradient behavior during steel static solidification for different mold thicknesses; thermal gradient seems to be temporarily constant when the CET occurs; the $C(0.3) \div E(0.3)$ time interval corresponds with the $t_{C}^{R} \div t_{E}^{R}$ period, Fig. 1; ABAQUS - simulation

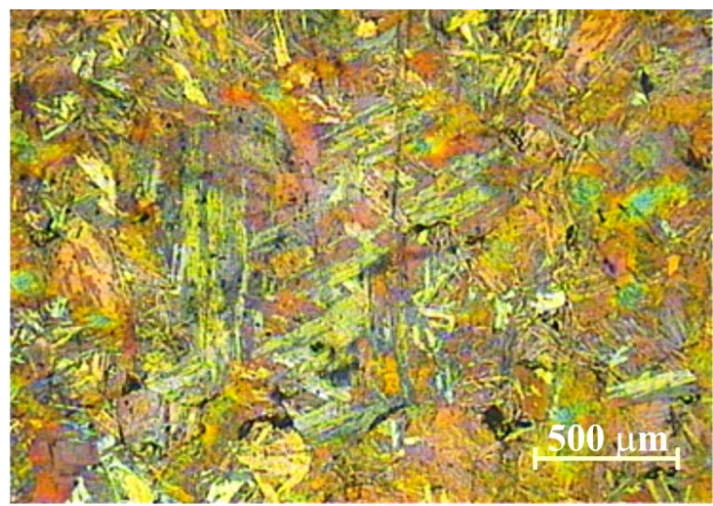

Fig. 4. Columnar- and equiaxed structure co-existence as revealed within the 15-tons steel forging ingot at its vertical cut at the middepth

The performed simulations of the thermal gradient behavior in time, Fig. 3, confirmed by the steel structure observations prove that the equiaxed structure is dominant in the steel static ingot. On the other hand, the columnar structure is usually privileged in the continuously cast brass ingot, Fig. 2. Thus, it would be interesting to predict the structural zones in a virtually cast brass static ingot.

\subsection{Mathematical forecast of structural zones' formation in a virtual brass static ingot}

A recently developed numerical model for the continuous casting [23], [24], is modified / applied to the current method for the structural zones forecast. This model, to certain extent, develops the simulation manner applied previously in similar methods of temperature field calculation, [25]-[30]. Thus, the heat balance is introduced, Eq. (1).

$c_{e f}(T) \cdot \rho(T) \cdot \frac{\partial T}{\partial t}=\frac{\partial}{\partial r}\left[\lambda(T) \cdot \frac{\partial T}{\partial r}\right]+\frac{\lambda(T)}{r} \cdot \frac{\partial T}{\partial r}$

$T=T(t, r), \quad r \in\left[0, R_{m}\right]$, Fig. 6,

$c_{e f}(T)= \begin{cases}c_{b}(T), & T<T_{S} \\ c_{b}(T)+\frac{L}{T_{L}-T_{S}}, & T_{S} \leq T \leq T_{L} \\ c_{b}(T), & T>T_{L}\end{cases}$

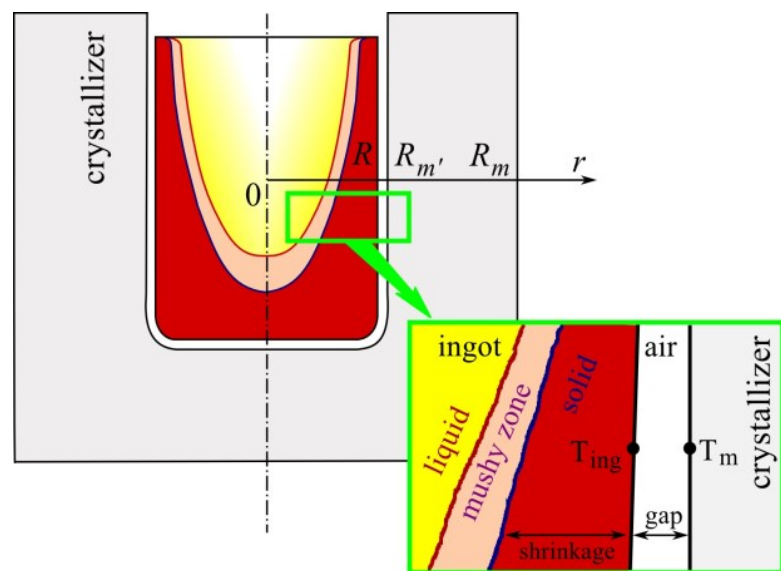

Fig. 5. Model of the virtual system for the static casting of the brass ingots as shown in the $x, r$ - coordinates; $T_{\text {ing }}$ - temperature of the solid shell surface; $T_{m}$ - temperature of the crystallizer / mold surface; expanding air gap due to shrinkage phenomenon and mushy zone are applied to the outline.

Eq. (1) requires to consider some boundary conditions, particularly, connected with the air gap as suggested in [31], [32], Fig. 5:

a) surface of solid shell being in contact with an air gap, Fig. 5,

$$
\left.\lambda(T) \frac{\partial T}{\partial r}\right|_{r=R}=\frac{\lambda_{g}}{\delta_{g}}\left(\left.T\right|_{r=R+\delta_{g}}-\left.T\right|_{r=R}\right)+\sigma\left[\left(\left.T\right|_{r=R+\delta_{g}}\right)^{4}-\left(\left.T\right|_{r=R}\right)^{4}\right]
$$


b) surface of graphite layer deposited on the crystallizer and being in contact with an air gap,

$$
\left.\lambda_{g r}(T) \frac{\partial T}{\partial r}\right|_{r=R+\delta_{g}}=\frac{\lambda_{g}}{\delta_{g}}\left(\left.T\right|_{r=R+\delta_{g}}-\left.T\right|_{r=R}\right)+\sigma\left[\left(\left.T\right|_{r=R+\delta_{g}}\right)^{4}-\left(\left.T\right|_{r=R}\right)^{4}\right]
$$

where, $\rho$ is density; $c b$ - brass specific heat; $\lambda_{g}, \lambda_{g r}$ - thermal conductivity coefficient in gap air, and graphite, respectively; $\delta_{g}$ thickness of air gap; $\sigma$ - Stefan - Boltzmann constant of radiation; $T$ - temperature; $T_{L}$ - liquidus isotherm temperature; $T_{S}$ - solidus isotherm temperature; $L$ - latent heat; $t$ - time; $r$ - radius of the system, Fig. 5.

It is postulated, in the current analysis, that the above method of calculation, Eq. (1), primarily predicted for continuous casting description can be applied to the simulation of thermal gradient field which is created during solidification of the virtual static brass ingot. It seems possible to determine the structural zones in the static ingot, analogously with the structure predictions made for the continuous casting, [33], [34].

The following structural transformations: FCCT (fine columnar into columnar structure) and CET (columnar into equiaxed structure transition) have been forecast. Both mentioned transitions are shown on the function presenting some changes of the thermal gradient at the s/l interface in function of time, Fig. 6. It is assumed that predicted two structural transitions correspond to the points of inflection which appear on this function. Moreover, the quasi-stationary period of an ingot solidification is revealed when the function has a linear course, Fig. 6.

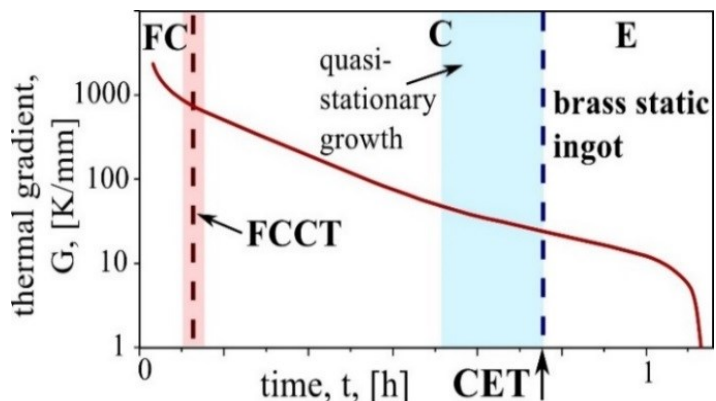

Fig. 6. Thermal gradient changes at the solid / liquid interface during a virtual brass static ingot solidification; FCCT and CET are forecast

The mathematical treatment of the above function, allows to conclude that the FCCT and CET - structural transitions are rather the sharp transformations. Three types of structural zones are distinguished: FC, C, and E. An extrapolation of the function from the FC - zone to zero seems to be completed just at the CET - appearance, as expected intuitively, Fig. 6.

The analogous analysis dealing with the forecast of structural zones is done in the STSM (Space-Time-Structure Map), Fig. 7.

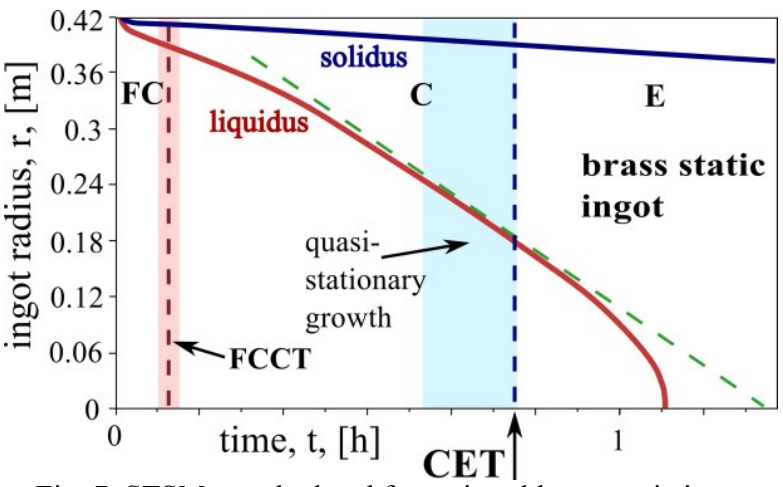

Fig. 7. STSM as calculated for a virtual brass static ingot solidification

Additionally, the same forecast is shown for the liquidus velocity behavior in function of solidification time, Fig. 8 .

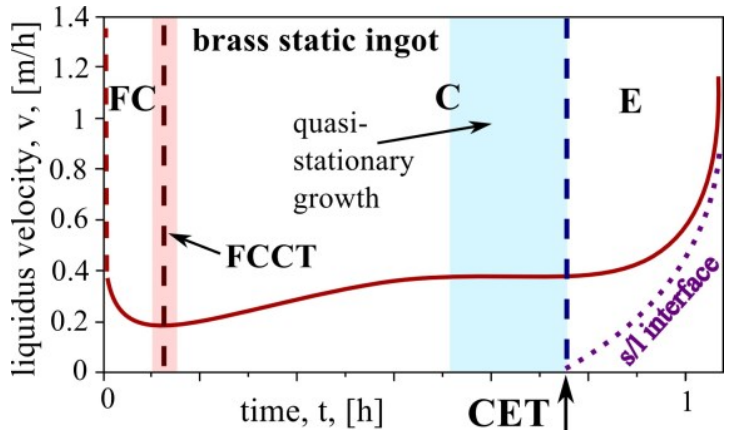

Fig. 8. Liquidus velocity versus solidification time for a virtual brass static ingot solidification; both transitions are at the local minima

The above analysis of the structural zones formation in the virtual brass static ingot (as well as in the steel static ingot, Fig. 1) is performed to facilitate the analogous comparison / forecast for the structural zones' formation during the continuous casting of the brass ingots with the similar zones in the steel static ingots.

\section{Concluding remarks}

The structural zones formation in the steel static massive ingot is investigated through the thermal gradient behavior in function of the varying mold thickness, Fig. 3 . The CET appears when the thermal gradient is temporarily constant. The CET is time consuming transition as confirmed by the structural observations on the longitudinal section of the 15-tones steel forging ingot, Fig. 4. Additionally, this structural transformation (CET) is confirmed theoretically, as occurring within the $t_{C}^{R} \div t_{E}^{R}$ time period, Fig. 1 .

The heat transfer model for the continuously cast brass ingot is also presented, Eq. (1). Sophistically, it is applied to the simulation of both temperature field and thermal gradient field in the virtually solidifying brass static ingot. It allows for mathematical forecast of the structural zones appearance in the studied brass static ingot. This forecast follows the recently 
developed method for structural zones' prediction in the solidifying steel static large ingot, Fig. 1 .

This mathematical manner of the structural zones' prediction leads to distinguish the following types of structures: a/ FC - fine columnar, b/ C - columnar, c/ E - equiaxed, Fig. 6.

The corresponding structural transformations like: $F C \rightarrow C$, and $C \rightarrow E$ appear as sharp changes of the adequate structures, mathematically connected with the points of inflection, Fig. 6.

The above forecast of structural zones appearance are confirmed in the Space-Time-Structure Map, Fig. 7, (at some points of inflection) and at the extreme points (minima) in Fig. 8.

\section{Acknowledgements}

The support was provided by the National Center for Research and Development under Grant No. PBS3/A5/52/2015. The assistance of the steel plant "CELSA - Huta Ostrowiec" in Ostrowiec Świętokrzyski, and in particular, Mr. R. Martynowski, is greatly appreciated.

\section{References}

[1] Wołczyński, W. (2016). Large Steel Ingots: Microstructure Mathematical Modeling. In Taylor \& Francis; R. Colas, G.E. Totten (Eds.), The Encyclopedia of Iron,.Steel, and Their Alloys. (pp. 1910-1924). Boca Raton-London-New York.

[2] Hunt, J.D. (1984). Steady State Columnar / Equiaxed Growth of Dendrites and Eutectics. Materials Science and Engineering. 65, 75-83.

[3] Alexandrova, I.V., Alexandrov, D.V., Aseev, D.L. \& Bulitcheva, S.V. (2009). Mushy Layer Formation during Solidification of Binary Alloys from a Cooled Wall: the Role of Boundary Conditions. Acta Physica Polonica A. 115, 6-9.

[4] Wołczyński, W., Lipnicki, Z., Bydałek, A.W., \& Ivanova, A.A. (2016). Structural Zones in Large Static Ingots. Forecasts for Continuously Cast Brass Ingot. Archives of Foundry Engineering. 16(3), 141-146.

[5] Suzuki, K., \& Taniguchi, K. (1981). The Mechanism of Reducing "A" Segregates in Steel Ingots. Transactions of the Iron and Steel Institute of Japan. 21(4), 235-242.

[6] Gandin, Ch. A., Rappaz, M., \& Tintillier, R. (1994). Three Dimensional Simulation of the Grain Formation in Investment Casting. Metallurgical Transactions. 25A, 629641.

[7] Gandin, Ch.A. (2000). From Constrained to Unconstrained Growth during Directional Solidification. Acta Materialia. 48, 2483-2501.

[8] Szajnar, J. (2004). The Columnar Crystals Shape and Castings Structure Cast in Magnetic Field. Journal of Materials Processing Technology. 157/158, 761-764.

[9] Martorano, M.A., Beckerman, C., \& Gandin, Ch, A. (2004). Solutal Interaction Mechanism for Columnar-to-Equiaxed Transition in Alloy Solidification. Metallurgical and Materials Transactions. 35A, 1915-1922.

[10] Billia, B., Gandin, Ch.A., Zimmerman, G., Browne, D.J, \& Dupouy, M. (2005). Columnar - Equiaxed Transition in
Solidification Processing. Microgravity Science and Technology. 16, 290-298.

[11] Nguyen-Thi, H., Zhou, B.H., Reinhart, G., Billia, B., Liu, Q.S., Lan, C.W., Lyubimova, T., \& Roux, B. (2006). Influence of Forced Convection on Columnar Microstructure during Directional Solidification of Al-Ni Alloys. Materials Science Forum. 508, 181-186.

[12] McFadden, S., Browne, D.J., \& Banaszek, J. (2006). Prediction of the Formation of an Equiaxed Zone ahead of a Columnar Front in Binary Alloys Castings: Indirect and Direct Methods. Materials Science Forum. 508, 325-330.

[13] Szajnar, J., Stawarz, M., Wróbel, T. \& Sebzda, W. (2009) Influence of Electromagnetic Field on Pure Metals and Alloys Structure. Journal of Achievements in Materials and Manufacturing Engineering. 34, 95-102.

[14] McFadden, S., Browne, D.J., \& Gandin, Ch.A. (2009). A Comparison of CET Prediction Methods using Simulation of the Growing Columnar Front. Metallurgical Transactions. 40A, 662-672.

[15] Konozsy, L., Ishmurzin, A., Grasser, M., Wu, M.H., Ludwig, A., Tanzer, R, \& Schutzenhofer, W. (2010). Columnar to Equiaxed Transition during Ingot Casting using Ternary Alloy Composition. Materials Science Forum. 649, 349-354.

[16] Cholewa, M., Wróbel, T., \& Tenerowicz, S. (2010). Bimetallic Layer Castings. Journal of Achievements in Materials and Manufacturing Engineering. 43, 385-392.

[17] Lorbiecka, A.Z., \& Sarler, B. (2010). Simulation of Dendritic Growth with Different Orientation by Using the Point Automata Method. Computers, Materials and Continua. 18(1), 69-103.

[18] Miyata, Y. (2010). Morphological Transition in High Growth Rate in Constrained Solidification. Materials Science Forum. 649, 255-262.

[19] McFadden, S., Browne, D.J., Sturz, L., \& Zimmermann, G. (2010). Analysis of a Microgravity Experiment for Columnar to Equiaxed Transitions with Modeling Results. Materials Science Forum. 649, 361-366.

[20] Wróbel, T. (2011). Bimetallic Layered Castings Alloy Steel Grey Cast Iron, Archives of Materials Science and Engineering. 48, 118-125.

[21] Zimmermann, G., Sturz, L., Billia, B., Mangelinck-Noel, N., Liu, D.R., Nguyen-Thi, H., Bergeon, N., Gandin, Ch.A., Browne, D.J., Beckermann, Ch., Tourret, D., \& Karma, A. (2014). Columnar-to-Equiaxed Transition in Solidification Processing of AlSi7 Alloys in Microgravity - CETSOL Project. Materials Science Forum. 790/791, 12-21.

[22] Zyska, A., Konopka, Z. Łągiewka, M., \& Nadolski, M. (2016). Modelling of the Dendritic Crystallization by the Cellular Automaton Method. Archives of Foundry Engineering. 16(1) 99-106.

[23] Ivanova, A.A. (2009). Dynamika Tiemperaturnych Gradientow Nieprerywnolitogo Slitka, Metallurgicheskije Processy i Oborudovanije. 2(16), 7-12 (in Russian).

[24] Ivanova, A.A. (2012). Calculation of Phase Change Boundary Position in Continuous Casting. Archives of Foundry Engineering. 13(4), 57-62.

[25] Umeda, T. (1997). Heat, Mass and Microstructure Simulation of Continuous Casting. Proceedings of 7-th 
International Symposium on Physical Simulation, Tsukuba, Japan, June 3-7, 64-75.

[26] M'Hamdi, M., Bobadilla, M., Combeau, G., \& Lesoult, G. (1998). Numerical Modeling of the Columnar to Equiaxed Transition in Continuous Casting of Steel. Modelling of Casting, Welding and Advanced Solidification Process VIII, Proceedings of the VIII-th Conference on Modeling of Casting, Welding and Advanced Solidification, San Diego, California, USA, June 7-12, 1998, Thomas, B.G. Beckerman, Ch., Eds., T.M.S., Warrendale, Pennsylvania, 375.

[27] Majchrzak, E., Mochnacki, B., Dziewoński, M. \& Jasiński, M. (2008). Identification of Boundary Heat Flux on the Continuous Casting Surface. Archives of Foundry Engineering. 8(4), 105-110.

[28] Telejko, T., Malinowski, Z. \& Rywotycki, M. (2009). Analysis of Heat Transfer and Fluid Flow in Continuous Steel Casting. Archives of Metallurgy and Materials. 54, 837-844.

[29] Lorbiecka, A. \& Sarler, B. (2010). A Sensitivity Study of Grain Growth Model for Prediction of ECT/CET Transformations in Continuous Steel Casting. Materials Science Forum. 649, 373-378.
[30] Stetina, J., Kavicka, F., \& Mauder, T. (2011). Numerical Model of Heat Transfer and Mass Transfer during Solidification of Concasting Steel. Proceedings of the ASME/JSME 8-th Thermal Engineering Joint Conference AJTEC, Honolulu, Hawaii, USA, March 13-17, Eds. ASME/JSME Conference CD, AJTEC-44031, 2.1.

[31] Lipnicki, Z. \& Weigand, B. (2011). Influence of Thermal Boundary Layer on the Contact Layer between Liquid and a Cold Plate in a Solidification Process. Heat and Mass Transfer. 47, 1629-1635.

[32] Lipnicki, Z. \& Pantoł, K. (2015). Role of a Continuous Casting Forms on the Shape of the Solidified Crust. Archives of Metallurgy and Materials. 60(4), 2553-2557.

[33] Burbelko, A., Falkus, J., Kapturkiewicz, W., Sołek, K., Drożdż, P., \& Wróbel, M. (2012). Modeling of the Grain Structure Formation in the Steel Continuous Ingot by CAFE Method. Archives of Metallurgy and Materials. 57, 379-384.

[34] Tkadlečkova, M., Valek, L., Socha, L., Saternus, M., Pieprzyca, J., Merder, T., Michalek, K., \& Kovac, M. (2016). Study of Solidification of Continuously Cast Steel Round Billets using Numerical Mode. Archives of Metallurgy and Materials. 61(1), 221-226. 